\title{
Cancer survivors' perspectives on delivery of survivorship care by primary care physicians: an internet-based survey
}

Ernestina Nyarko ${ }^{1}$, James M. Metz ${ }^{2,4}$, Giang T. Nguyen ${ }^{3,4,5}$, Margaret K. Hampshire ${ }^{2,4}$, Linda A. Jacobs ${ }^{4}$ and Jun J. Mao $3,4,5^{*}$

\begin{abstract}
Background: Helping cancer survivors to transition from active treatment to long-term survivorship requires coordinated efforts by both oncologists and primary care physicians (PCPs). This study aims to evaluate cancer survivors' perspectives on PCP-delivered survivorship care.

Methods: We conducted an Internet-based cross-sectional survey of cancer survivors via www.OncoLink.org. Regression analyses were used to identify factors associated with perception of PCP-delivered survivorship care.

Results: The 352 respondents rated overall PCP-delivered survivorship care as 60 out of $100(S D=23)$. The areas of care most strongly endorsed were general care (62\%), psychosocial support (65\%), and holistic care (68\%). Survivors were less likely to perceive their PCPs as knowledgeable about cancer follow-up (43\%), late or long-term effects of cancer therapy (45\%), and diagnosis and treatment of symptoms related to cancer or cancer therapy (42\%). While $72 \%$ of survivors reported satisfaction with their PCP's care overall, only $41 \%$ felt that their PCPs and oncologists communicated well with one another. In a multivariate regression analysis, higher trust in PCP ( $p<$ $0.001)$, non-white race $(p=0.001)$, living in the United States $(p=0.007)$, and visiting a PCP two or more times per year $(p=0.009)$ were significantly associated with higher ratings of PCP-delivered survivorship care.

Conclusions: While cancer survivors in general are satisfied with care delivery by PCPs, they perceived that their PCPs have limited abilities in performing cancer-specific follow-up and late effect monitoring and treatment. Better education of family physicians about survivorship issues and improved communication between PCPs and oncologists are needed to improve PCPs' delivery of survivorship care.
\end{abstract}

Keywords: Cancer, Survivor, Perspective, Primary Care, Internet, Survey, Race, Quality of Care, Trust

\section{Background}

With improved surveillance, early detection, and treatment of cancer, the number of cancer survivors living beyond the active treatment phase is increasing in the United States. As of 2007, there were 12 million cancer survivors living in the United States, up from 9.8 million in 2001 and 3 million in 1971. The largest groups of cancer survivors were female breast cancer survivors (22.1\%), prostate cancer survivors $(22.1 \%)$, and colorectal cancer

\footnotetext{
* Correspondence: maoj@uphs.upenn.edu

${ }^{3}$ Department of Family Medicine and Community Health, University of Pennsylvania, 227 Blockley Hall, 423 Guardian Drive, Philadelphia, PA 19104-6021, USA

${ }^{4}$ Abramson Cancer Center, University of Pennsylvania, Pennsylvania, USA Full list of author information is available at the end of the article
}

survivors (9.5\%) [1]. As cancer survivors live decades beyond their initial cancer diagnosis, they are at risk for developing a number of physical and psychosocial conditions and late or long-term effects that are independent of their cancer or treatment. Survivors may experience chronic pain, fatigue, sleep problems, cognitive issues, sexual dysfunction, ongoing depression/ distress, fear of recurrence, and changes in their overall quality of life [2]. Studies in breast cancer survivors have found high prevalence of these symptoms among survivors [3-6]. Lung, colon, and prostate cancer survivors have also reported significant and persistent physical, psychosocial, sexual, and marital 
problems for years after disease remission that significantly impact their quality of life [7].

Traditionally, cancer patients receive healthcare through medical, surgical, or radiation oncologists for issues that arise during active cancer treatment and the initial posttreatment surveillance period. Thus, these providers have been thought of as the first line in addressing survivors' needs when cancer-related or treatment-related sequelae arise. However, studies show that while cancer survivors visit oncologists frequently during active treatment, the percentage of survivors who visit oncologists and cancerrelated specialists declines each year following active treatment. While survivors visit their oncologists less and less as time passes, the percentage of survivors who visit their primary care physician (PCP) each year is consistently high at around $75 \%$ and does not decline as survivors get further out from initial diagnosis $[8,9]$. This means that as time progresses, the vast majority of cancer survivors will present to their PCPs instead of their oncologists for evaluation and management of late and long-term effects. The PCP can play a critical role in the management of a cancer survivor's health by delivering preventive and general care as well as managing co-morbid conditions that may be unrelated to the cancer. Consequently, a team effort is required in order to assure that relevant information regarding cancer treatment, surveillance schedule, and general survivorship issues is communicated to the PCP by the oncology team [10].

Unfortunately, the transition of care from oncology to primary care is often fragmented and uncoordinated. A 2005 Institute of Medicine (IOM) report revealed that many cancer survivors felt uncertain about the care they receive once they transition from the care of their oncologists at the end of their cancer treatment course. Consequently, the IOM recommended a cancer treatment survivorship care plan for cancer survivors during the transition period that outlines information for long-term care including cancer diagnosis, treatment, potential consequences of treatment and guidelines for follow-up visits, general tips on healthy living and prevention of new and recurrent cancers, and the availability of psychosocial and legal support services [11]. Interestingly, research done to date demonstrates that family physicians are able to provide care that is similar in quality and outcomes as that provided by oncology specialists for breast cancer survivors [12]. However, a recent study found that survivorship care planning did not improve patient-reported outcomes and health care service utilization compared to standard care in the same type of population [13, 14]. In order to deliver the comprehensive, coordinated care suggested by the IOM, PCPs must become more comfortable with the delivery of cancer survivorship care. Since 2005, several surveys of primary care physicians and oncologists have been conducted which indicate that both PCPs and oncologists acknowledge the importance of primary care physician involvement in new models of survivorship care delivery and are willing to work toward improving the transition of care [15-21].

While it is important to understand the views of PCPs and oncologists regarding the transfer of cancer survivorship care from primarily oncology-based to PCP-based, it is vital to incorporate cancer survivor perspectives as we move toward designing and implementing new models of patient-centered survivorship care. To date, few studies have examined cancer survivor perspectives on the delivery of survivorship care by primary care physicians. The few studies of survivor perspectives of PCP-delivered survivorship care have focused primarily on patients presenting to urban or university-affiliated cancer centers [22-24]. In this study, we used an Internet-based survey to quantify cancer survivor perspectives of PCPdelivered survivorship care. Our aim in using an Internet-based survey was to gather information from more geographically diverse groups of cancer survivors underrepresented in the current literature.

\section{Methods}

\section{Study design and respondent population}

Between July 2009 and June 2012, an Internet-based questionnaire assessing patient demographics and perceptions of primary care physician-delivered survivorship care was intermittently (few days every few months) posted on the OncoLink website (http://www.oncolink.org). OncoLink, one of the oldest and largest Internet-based cancer information resources, serves close to 1.5 million web pages and receives more than 189,000 visits from unique IP addresses per month. OncoLink is available to anyone who has access to the Internet. Currently, $75 \%$ of OncoLink's user base is from the United States, while $25 \%$ access the website from international locations [25].

The study questionnaire was composed of 30 items assessing patient demographics, primary cancer diagnoses, treatment modalities used, setting of cancer treatment, use of primary care and specialty care, relationship with primary care physician and perceptions of survivorship care delivery by primary care physicians. The questionnaire was randomly rotated on the homepage and other high profile locations on the website. There was no use of external advertising or directed e-mail announcements. Study participants voluntarily and anonymously completed the survey instrument after reading an online informed consent document. Survey questions and responses were maintained on a physically and electronically secure server and downloaded for analysis. This cross-sectional study was approved by the University of Pennsylvania Institutional Review Board. 


\section{Primary outcome measure}

The primary outcome measure was a seven-item Primary Care Delivery of Survivorship Care Scale (PCDSCS) [24]. Each item on the PCDSCS is scored on a 5-point Likert scale from 0 to 4 . The scale scores had an excellent internal consistency with a Cronbach's alpha of 0.89. Principal component analysis yielded one factor with eigenvalue of 3.89. The higher score was correlated with greater trust in PCPs. The total score was transformed and placed on a 100-point scale with higher number indicating better perceived care delivery by PCPs [24].

\section{Covariates}

Respondents reported demographic, cancer-related, and healthcare-related variables. Demographic variables included age, sex, race, educational level, residential area, and country of residence. Cancer-related variables included type of cancer, type of treatment (s) received, and age at cancer diagnosis. Healthcare-related variables included type of physician managing care, whether the respondent has been offered survivorship care, distance to and setting of the respondent's cancer treatment center, and length and frequency of relationship with their primary care physician. Respondents also rated communication between their PCP and oncologist and trust that their PCP works toward the respondent's best interests as a patient. Trust in PCP was rated on a numerical scale from 1 to 10 with 10 indicating highest trust. Because this variable was not normally distributed, we dichotomized at the median value as high vs. low trust.

\section{Statistical analysis}

Statistical analysis was performed using STATA 12.0 for Windows (STATA Corp, College Station, TX). Bivariate regression analysis was used to select patient characteristics associated with the outcome variable, PCDSCS. Variables that showed a strong association $(p<0.1)$ were then used to generate a multivariate regression model to further characterize patient variables associated with perceived survivorship care delivery by PCPs. All analyses were two-sided with $p<0.05$ indicating statistical significance. Chi-square analyses of individual PCDSCS statement endorsement were performed to determine which aspects of PCP survivorship care delivery might explain significant differences observed between groups in multivariate regression. Respondents were considered to endorse a particular aspect of PCP survivorship care delivery if they answered "Agree" or "Strongly agree" in response to the corresponding item on the survey instrument.

\section{Results}

\section{Respondent characteristics}

The mean age for the 352 cancer survivors who responded to the Internet survey was 54.1 years. Two hundred and ninety-three respondents $(83.5 \%)$ were female and 58 (16.5\%) were male. Racially, 277 (79.8 \%) were Caucasian, 36 (10.4 \%) were Asian or Pacific Islander, 15 (4.3\%) were African-American, 9 (2.6 \%) were Hispanic or Latino, 6 (1.7\%) were of mixed race, and $4(1.2 \%)$ considered themselves to be of another race. One hundred and thirty-six (39.3\%) lived in urban areas, 151 (43.6 \%) lived in suburban areas, and 59 $(17.1 \%)$ lived in rural areas. Two hundred and thirtytwo $(66.5 \%)$ respondents held a college degree (BA, BS) or higher. Respondents included survivors of thirty different cancer types. Of these, 149 (43.1\%) were breast cancer survivors, 19 (5.5\%) were lung cancer survivors, 18 (5.2\%) were colon cancer survivors, 15 (4.3\%) reported a history of ovarian cancer, and 11 (3.2\%) were prostate cancer survivors. One hundred and thirtyseven (39.9\%) received cancer care exclusively at university-based cancer centers, while 150 (43.7\%) reported receiving cancer care at community-based nonuniversity affiliated centers. Two hundred and eightytwo respondents $(81.5 \%)$ were living in the United States, 8 (2.3\%) were living in Canada, and 56 (16.2\%) reported living in sixteen other countries. Respondents living in the United States were from forty of the fifty states and represented all four census regions of the country. Of the 243 respondents who indicated their state of residence, 88 (36.2\%) were from the Northeast, $63(25.9 \%)$ were from the West, $57(23.5 \%)$ were from the South, and 35 (14.4\%) were from the Midwest. For data analysis purposes, race was dichotomized as Caucasian or non-Caucasian and cancer type was dichotomized as breast or non-breast to enhance the power when analyzing these variables.

\section{Respondent rating of Primary Care Delivery of Survivorship Care Scale (PCDSCS)}

Overall, respondents rated primary care physician delivery of survivorship care 59.8 out of 100 (median 60.7, SD 22.7). Respondents most strongly endorsed primary care physician delivery of holistic care $(66.8 \%)$, psychosocial support $(64.2 \%)$, and general care $(61.1 \%)$ that enables patients to live healthier lives. Respondents were less likely to perceive PCPs as knowledgeable in the following domains of care: appropriate cancer follow-up care $(42.3 \%)$, late or long-term effects of cancer therapy (44.3\%), and diagnosis and treatment of symptoms related to cancer or cancer therapy (41.8\%). Only $40.3 \%$ of respondents believed that their PCP communicates well with their oncologists in managing their care. Respondent trust in their PCP was high with a mean of 7.54 and a median of 8 (SD 2.64). Trust scores ranged from 0 to 10 , with $30.11 \%$ of respondents rating trust in their PCP as 10 out of 10. 
Table 1 PCDSCS Score and Respondent Characteristics

\begin{tabular}{|c|c|c|c|c|}
\hline \multirow[t]{2}{*}{ Characteristic } & \multicolumn{2}{|c|}{ Patients } & \multirow{2}{*}{$\begin{array}{l}\text { Mean } \\
\text { PCDSCS } \\
\text { score }\end{array}$} & \multirow[t]{2}{*}{$P$-value } \\
\hline & No. & $\%$ & & \\
\hline Age & & & & 0.34 \\
\hline $18-39$ & 69 & 21.2 & 57.8 & \\
\hline $40-64$ & 203 & 62.5 & 58.6 & \\
\hline 65 or older & 53 & 16.3 & 61.9 & \\
\hline Gender & & & & 0.92 \\
\hline Male & 58 & 16.5 & 59.6 & \\
\hline Female & 293 & 83.5 & 60.0 & \\
\hline Race & & & & 0.0035 \\
\hline White & 277 & 79.8 & 58.1 & \\
\hline Non-White & 70 & 20.2 & 67.0 & \\
\hline Education level & & & & 0.32 \\
\hline Less than college & 117 & 33.5 & 58.2 & \\
\hline $\begin{array}{l}\text { College degree (BA/BS) } \\
\text { or higher }\end{array}$ & 232 & 66.5 & 60.8 & \\
\hline Residence & & & & 0.062 \\
\hline Urban & 136 & 39.3 & 63.1 & \\
\hline Suburban & 151 & 43.6 & 56.8 & \\
\hline Rural & 59 & 17.1 & 59.1 & \\
\hline Country & & & & 0.0007 \\
\hline United States & 282 & 81.5 & 61.8 & \\
\hline Outside United States & 64 & 18.5 & 51.1 & \\
\hline Cancer type & & & & 0.75 \\
\hline Breast & 149 & 43.1 & 60.3 & \\
\hline Non-breast & 197 & 56.9 & 59.5 & \\
\hline Cancer center & & & & 0.65 \\
\hline University-based & 137 & 39.9 & 58.6 & \\
\hline Community-based & 150 & 43.7 & 61.1 & \\
\hline Both & 56 & 16.3 & 59.7 & \\
\hline Chemotherapy & & & & 0.55 \\
\hline Yes & 196 & 57.0 & 60.8 & \\
\hline No & 148 & 43.0 & 59.3 & \\
\hline Radiation therapy & & & & 0.018 \\
\hline Yes & 168 & 48.8 & 57.1 & \\
\hline No & 176 & 51.2 & 63.0 & \\
\hline Surgery & & & & 0.088 \\
\hline Yes & 212 & 61.6 & 58.5 & \\
\hline No & 132 & 38.4 & 62.8 & \\
\hline Hormone therapy & & & & 0.36 \\
\hline Yes & 106 & 30.8 & 58.4 & \\
\hline No & 238 & 69.2 & 60.9 & \\
\hline $\mathrm{PCP}$ visits per year & & & & 0.0015 \\
\hline Fewer than 2 & 101 & 28.9 & 53.6 & \\
\hline
\end{tabular}

Table 1 PCDSCS Score and Respondent Characteristics (Continued)

\begin{tabular}{|c|c|c|c|c|}
\hline 2 or more & 248 & 71.1 & 62.2 & \\
\hline Trust in PCP & & & & $<0.001$ \\
\hline Low & 138 & 39.2 & 43.5 & \\
\hline Higher & 214 & 60.8 & 70.3 & \\
\hline Care providers & & & & 0.059 \\
\hline PCP/Internist & 68 & 21.3 & 63.6 & \\
\hline Oncologist & 124 & 38.9 & 57.5 & \\
\hline Combination & 127 & 39.8 & 63.6 & \\
\hline Years known PCP & & & & 0.008 \\
\hline Less than 1 year & 63 & 18.5 & 52.5 & \\
\hline $1-4$ years & 108 & 31.8 & 64.6 & \\
\hline $5-9$ years & 76 & 22.4 & 60.3 & \\
\hline 10 or more years & 93 & 27.4 & 58.5 & \\
\hline
\end{tabular}

Respondent characteristics associated with PCDSCS score Table 1 shows the distribution of respondents and PCDSCS scores. In bivariate analysis, non-white race $(p=0.004)$, US residence $(p=0.001)$, and history of radiation therapy $(p=0.018)$ were significantly associated with higher PCDSCS scores. More frequent PCP visits $(p=0.002)$, higher trust in PCP $(p<0.001)$, and perceiving the PCP as one of the people with primary responsibility for patient care $(p<0.001)$ were also associated with higher PCDSCS scores. Interestingly, the setting of cancer treatment and type of cancer (breast or non-breast) were not significantly associated with PCDSCS rating.

In multivariate analysis, non-white race, US residence, and having two or more visits with the PCP annually were significantly associated with higher PCDSCS score ( $p=0.001,0.007$ and 0.009 respectively). Higher trust in PCP was strongly associated with higher PCDSCS score $(p<0.001$, Fig. 1$)$. Table 2 depicts the results of multivariate regression analysis.

\section{Respondent Endorsement of Individual Aspects of PCDSCS (Table 3)}

Chi-square analysis showed significant differences between white respondents and non-white respondents in perceived cancer-specific care; scores on general care and communication with oncologists did not differ significantly by race. United States residents were significantly more likely to agree that their PCP helps them live a healthier life by discussing diet and exercise weight management, but did not differ significantly from nonUS residents in the endorsement of other statements on PCP delivery of survivorship care. High trust in PCP showed the strongest relationship with individual statement 


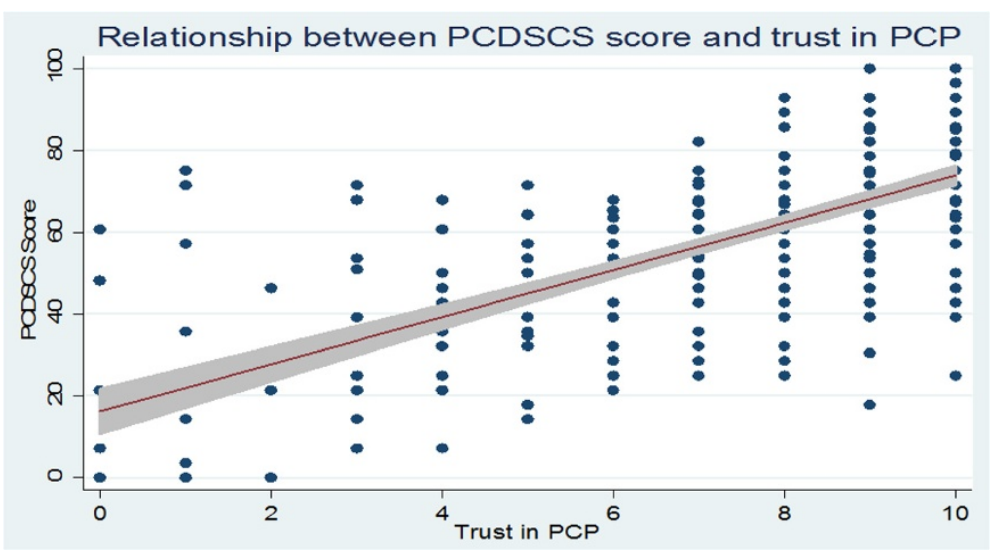

Fig. 1 Relationship between PCDSCS score and trust in PCP

endorsement; respondents reporting higher trust in their PCP rated all aspects of PCP care delivery significantly higher than respondents reporting lower trust in their PCP.

\section{Discussion}

Although there is much interest in the literature on constructing new models of cancer survivorship care, few studies have quantified cancer patients' perspectives of survivorship care by primary care physicians who are the principal caretakers of cancer survivors after the initial treatment and surveillance period. We found that survivors generally believe that their PCPs provide high quality primary care, psychosocial support, and holistic care, which is consistent with a prior trial demonstrating that breast cancer survivors had high satisfaction with their PCPs [26] and experienced a similar health-related quality of life as if they were cared by specialists [12]. However survivors were less confident in their PCPs' ability to provide knowledgeable, appropriate cancer-specific care. These findings are consistent with previous studies of breast and prostate cancer survivors[24, 27], emphasizing the need for improving education for PCPs on cancer-specific follow up care.

This study found that non-white patients and patients who visit their PCP more frequently rate PCP delivery of survivorship care significantly higher. The association between non-white race and PCDSCS score may be explained by differences among white patients and minority patients in what they consider to be important components of quality healthcare. A recent study shows that while patients of all racial groups perceive short waiting times, good patient-provider rapport, physician competence, and respect for the patient as important components of quality healthcare, minority patients also cited holistic care that addresses their physical, spiritual, and emotional needs as an important component of quality healthcare [28]. While, the provision of holistic or whole-person care as opposed to disease or organ- specific care may be more appreciated by non-white patients and may contribute to higher ratings of the PCDSCS score, our results also show that non-white patients rate PCP delivery of cancer-specific care more highly than white patients, a finding that calls for further exploration.

The relationship between PCDSCS score and the frequency of visits to the primary care physician can be explained in several ways. More frequent visits with the PCP allow more opportunities for building trust and rapport between patients and their PCP, which likely explains some of our observed association. Furthermore, the literature shows that more frequent PCP visits may be associated with receipt of more appropriate care, which would increase patient satisfaction. For example, a study of prostate cancer patients showed that patients who visited their PCP more frequently were more likely to receive influenza vaccinations, colorectal cancer screening, and cholesterol screening at recommended intervals [29].

An interesting new finding of this study is the significantly higher rating of PCDSCS by survivors living in the United States when compared with those living outside the US. While there may be differences in perceptions of what constitutes high quality care in different countries [30], this finding merits further study if we hope to design successful models of patient-centered survivorship care that will be applicable worldwide. Given that each country has unique health care delivery and health service reimbursement systems, it is likely one size won't fit all. However, the importance of trust between a physician and patient transcends cultures and health systems. Our study found that survivors generally trust their primary care physicians. If educational systems or institutions provide pathways for PCPs to increase their knowledge of cancer-specific follow-up, surveillance, and diagnosis and treatment of late effects, the high level of trust survivors have in their PCPs will 
Table 2 Multivariate Regression Analysis of Respondent Characteristics and PCDSCS Score

\begin{tabular}{|c|c|c|c|c|c|c|}
\hline \multirow[b]{2}{*}{ Characteristic } & \multicolumn{3}{|c|}{ Unadjusted analysis } & \multicolumn{3}{|c|}{ Adjusted analysis } \\
\hline & Coefficient & $95 \% \mathrm{Cl}$ & $P$-value & Coefficient & $95 \% \mathrm{Cl}$ & $P$-value \\
\hline \multicolumn{7}{|l|}{ Race } \\
\hline \multicolumn{7}{|l|}{ Caucasian (reference) } \\
\hline Non-Caucasian & 8.93 & 2.95 to 14.91 & 0.004 & 9.74 & 3.9 to 15.6 & 0.001 \\
\hline \multicolumn{7}{|l|}{ Residence } \\
\hline \multicolumn{7}{|l|}{ Urban (reference) } \\
\hline Suburban & -6.32 & -11.6 to -1.0 & 0.019 & -2.00 & -6.5 to 2.5 & 0.39 \\
\hline Rural & -3.96 & -10.9 to 3.0 & 0.26 & -1.65 & -7.8 to 4.5 & 0.60 \\
\hline \multicolumn{7}{|l|}{ Country } \\
\hline \multicolumn{7}{|l|}{ United States (reference) } \\
\hline Outside United States & -10.71 & -16.8 to -4.6 & 0.001 & -7.94 & -13.6 to -2.2 & 0.007 \\
\hline \multicolumn{7}{|l|}{ Radiation therapy } \\
\hline Yes & -5.86 & -10.7 to -1.0 & 0.018 & -3.88 & -8.0 to 0.3 & 0.069 \\
\hline \multicolumn{7}{|l|}{ No (reference) } \\
\hline \multicolumn{7}{|l|}{ Surgery } \\
\hline Yes & -4.34 & -9.3 to 0.6 & 0.088 & -1.88 & -6.4 to 2.6 & 0.41 \\
\hline \multicolumn{7}{|l|}{ No (reference) } \\
\hline \multicolumn{7}{|l|}{$P C P$ visits per year } \\
\hline \multicolumn{7}{|l|}{ Fewer than 2 (reference) } \\
\hline 2 or more & 8.57 & 3.3 to 13.8 & 0.002 & 6.22 & 1.6 to 10.9 & 0.009 \\
\hline \multicolumn{7}{|l|}{ Trust in PCP } \\
\hline \multicolumn{7}{|l|}{ Low (reference) } \\
\hline High & 26.81 & 22.8 to 30.8 & $<0.001$ & 26.47 & 22.1 to 30.8 & $<0.001$ \\
\hline \multicolumn{7}{|l|}{ Care provider } \\
\hline \multicolumn{7}{|l|}{ PCP only (reference) } \\
\hline Oncologist only & -6.14 & -12.8 to 0.5 & 0.07 & -4.91 & -10.2 to 0.4 & 0.070 \\
\hline Both PCP and Oncologist & -0.01 & -6.6 to 6.6 & 1.00 & -3.04 & -8.4 to 2.3 & 0.26 \\
\hline \multicolumn{7}{|l|}{ Years known PCP } \\
\hline \multicolumn{7}{|l|}{ Less than 1 year (reference) } \\
\hline $1-4$ years & 12.16 & 5.1 to 19.2 & 0.001 & 2.78 & -3.2 to 8.7 & 0.36 \\
\hline 5-9 years & 7.85 & 0.4 to 15.3 & 0.04 & -0.70 & -7.2 to 5.8 & 0.83 \\
\hline 10 or more years & 6.04 & -1.1 to 13.2 & 0.099 & -5.04 & -11.6 to 1.5 & 0.13 \\
\hline
\end{tabular}

Abbreviations: $P C D S C S$ primary care delivery of survivorship care scale, $P C P$ primary care physician

do much to advance survivor acceptance and increase survivor perceptions of PCP-delivered survivorship care.

Overall, this study indicates that cancer survivors have unfavorable perceptions of cancer-specific survivorship care delivered by PCPs. This finding is consistent with previous studies $[19,24,27,31]$ which show that although PCPs are willing to assume more responsibility for cancer survivorship care, they themselves feel that their training and familiarity with cancer surveillance guidelines are inadequate [16, 19, 20, 31-33]. Intervention studies have shown that survivorship care algorithms [12] and survivorship care courses [34] significantly improve PCP comfort with, and delivery of, appropriate cancer survivorship care. Future research should focus on developing models for training both upcoming and practicing PCPs in survivorship care delivery that can be implemented in various practice settings. Further studies should help elucidate the effect of this training on patient perceptions of PCP survivorship care delivery.

Several limitations to our study need to be acknowledged. First, this cross-sectional study relies on survivor 
Table 3 Respondent Endorsement of Individual Aspects of Primary Care Delivery of Survivorship Care

\begin{tabular}{|c|c|c|c|c|c|c|c|c|c|}
\hline \multirow[b]{2}{*}{ My primary care doctor... } & \multicolumn{2}{|c|}{ Race (\%) } & \multirow[b]{2}{*}{$P$-value } & \multicolumn{2}{|c|}{ Country (\%) } & \multirow[b]{2}{*}{ P-value } & \multicolumn{2}{|c|}{ Trust (\%) } & \multirow[b]{2}{*}{$P$-value* } \\
\hline & White & Non-White & & US & Non-US & & High & Low & \\
\hline Communicates well with my oncologist since my cancer diagnosis & 38.3 & 54.4 & 0.016 & 41.9 & 34.5 & 0.27 & 56.1 & 17.8 & $<0.001$ \\
\hline Is knowledgeable about appropriate follow-up for cancer survivors & 38.9 & 60.3 & $<0.001$ & 44.6 & 37.5 & 0.30 & 60.6 & 15.6 & $<0.001$ \\
\hline Is aware of potential long-term effects of cancer treatment & 42.3 & 61.8 & 0.004 & 47.6 & 37.5 & 0.14 & 59.9 & 24.4 & $<0.001$ \\
\hline $\begin{array}{l}\text { Is skilled at diagnosing and treating symptoms associated with } \\
\text { cancer or cancer therapy }\end{array}$ & 38.5 & 61.8 & 0.001 & 43.5 & 42.2 & 0.85 & 54.9 & 24.4 & $<0.001$ \\
\hline Pays attention to my emotional wellbeing & 65.1 & 70.6 & 0.39 & 68.7 & 54.7 & 0.033 & 84.0 & 37.8 & $<0.001$ \\
\hline $\begin{array}{l}\text { Helps me live a healthier life by discussing diet, exercise, and } \\
\text { weight management }\end{array}$ & 60.6 & 72.1 & 0.080 & 68.2 & 39.1 & $<0.001$ & 77.8 & 38.5 & $<0.001$ \\
\hline Is sensitive to my needs as a whole person & 69.0 & 75.0 & 0.33 & 72.6 & 57.8 & 0.021 & 87.3 & 43.0 & $<0.001$ \\
\hline
\end{tabular}

Abbreviation: US United States

*P-values calculated by Chi-square analysis

self-report instead of directly measuring PCP survivorship care delivery. Secondly, the use of an Internet-based survey creates selection bias in our study; cancer survivors who are over the age of 60 , minorities, or those who have lower education are less likely to have Internet access and are expected to be under-sampled and underrepresented in Internet-based research studies [35, 36]. Our research needs to be replicated in representative clinical or population based samples. Lastly, although our survey respondents have very heterogeneous tumor types and geographic representations, the smaller sample size in each of the specific categories prevents more indepth comparison among subgroups.

\section{Conclusions}

Despite its limitations, to our knowledge, this is the first Internet-based study of patient perspectives of cancer survivorship care delivery by primary care physicians. Through the use of a freely accessible Internet survey, our study allows for representation of cancer survivor populations that are otherwise under-represented in the current literature (e.g. in community setting, with nonbreast cancer, rural, and other countries) on cancer survivorship care. The high trust between survivors and their PCPs builds a strong foundation towards optimal care. While cancer survivors in general are satisfied with care delivery by PCPs, they perceived that their PCPs have limited abilities in performing cancer-specific follow-up and late effect monitoring and treatment.Our findings highlight that equipping PCPs with cancerspecific knowledge, skills, and confidence is necessary to deliver high quality care for diverse groups of cancer survivors.

\section{Abbreviations}

PCPs: Primary care physicians; PCP: Primary care physician; IOM: Institute of Medicine; PCDSCS: Primary care delivery of survivorship care scale; BA/

BS: Bachelor of arts or science.

\section{Competing interests}

We have no conflicts of interest to declare.

\section{Authors' contribution}

Dr. Nyarko performed statistical analysis and drafted the manuscript. She was supported by Pennsylvania Department of Health Translational Research Program for Minority Medical/Graduate Students. Dr. Metz helped interpret the data and revise the manuscript. Dr. Nguyen helped interpret the data and revise the manuscript. Ms. Hampshire helped interpret data and revise the manuscript. Dr. Jacobs helped interpret the data and revise the manuscript. Dr. Mao conceived of the study, helped perform the statistical analysis, and drafted the manuscript. All authors read and approved the final manuscript.

\section{Acknowledgement}

Dr. Mao is supported by the National Institutes of Health (1 K23 AT004112-05). The content is solely the responsibility of the authors and does not necessarily represent the official views of the National Institutes of Health. We thank all the participants for their time and contribution to our study.

\section{Author details}

${ }^{1}$ Perelman School of Medicine at the University of Pennsylvania, Pennsylvania, USA. ${ }^{2}$ Department of Radiation Oncology, University of Pennsylvania, Pennsylvania, USA. ${ }^{3}$ Department of Family Medicine and Community Health, University of Pennsylvania, 227 Blockley Hall, 423

Guardian Drive, Philadelphia, PA 19104-6021, USA. ${ }^{4}$ Abramson Cancer Center, University of Pennsylvania, Pennsylvania, USA. ${ }^{5}$ Center for Clinical

Epidemiology and Biostatistics, University of Pennsylvania, Pennsylvania, USA.

Received: 20 November 2014 Accepted: 9 October 2015

Published online: 20 October 2015

\section{References}

1. Centers for Disease Control and Prevention. Cancer survivors-United States, 2007. MMWR Morb Mortal Wkly Rep. 2011;60(9):269-72.

2. Howell D, Hack TF, Oliver TK, Chulak T, Mayo S, Aubin M, et al. Models of care for post-treatment follow-up of adult cancer survivors: a systematic review and quality appraisal of the evidence. J Cancer Surviv. 2012;6(4):35971.

3. Meeske K, Smith AW, Alfano CM, McGregor BA, McTiernan A, Baumgartner $K B$, et al. Fatigue in breast cancer survivors two to five years post diagnosis: a HEAL Study report. Qual Life Res. 2007;16(6):947-60.

4. Ganz PA, Rowland JH, Desmond K, Meyerowitz BE, Wyatt GE. Life after breast cancer: understanding women's health-related quality of life and sexual functioning. J Clin Oncol. 1998;16(2):501-14.

5. Ganz PA, Desmond KA, Leedham B, Rowland JH, Meyerowitz BE, Belin TR. Quality of life in long-term, disease-free survivors of breast cancer: a followup study. J Natl Cancer Inst. 2002;94(1):39-49.

6. Jiwa M, Thompson J, Coleman R, Reed M. Breast cancer follow-up: could primary care be the right venue? Curr Med Res Opin. 2006;22(4):625-30. 
7. Schag CA, Ganz PA, Wing DS, Sim MS, Lee JJ. Quality of life in adult survivors of lung, colon and prostate cancer. Qual Life Res. 1994;3(2):127-41.

8. Keating NL, Landrum MB, Guadagnoli E, Winer EP, Ayanian JZ. Surveillance testing among survivors of early-stage breast cancer. J Clin Oncol. 2007;25(9):1074-81.

9. Pollack LA, Adamache W, Ryerson AB, Eheman CR, Richardson LC. Care of long-term cancer survivors: physicians seen by Medicare enrollees surviving longer than 5 years. Cancer. 2009;115(22):5284-95.

10. Salz T, Oeffinger KC, Lewis PR, Williams RL, Rhyne RL, Yeazel MW. Primary care providers' needs and preferences for information about colorecta cancer survivorship care. J Am Board Fam Med. 2012;25(5):635-51.

11. Hewitt M, Greenfield S, Stovall E. From Cancer Patient to Cancer Survivor: Lost in Transition. Washington, DC: National Academies Press; 2006.

12. Grunfeld E, Levine MN, Julian JA, Coyle D, Szechtman B, Mirsky D, et al. Randomized trial of long-term follow-up for early-stage breast cancer: a comparison of family physician versus specialist care. J Clin Oncol. 2006;24(6):848-55

13. Grunfeld E, Julian JA, Pond G, Maunsell E, Coyle D, Folkes A, et al. Evaluating survivorship care plans: results of a randomized, clinical trial of patients with breast cancer. J Clin Oncol. 2011;29(36):4755-62.

14. Boekhout AH, Maunsell E, Pond GR, Julian JA, Coyle D, Levine MN, Grunfeld E: A survivorship care plan for breast cancer survivors: extended results of a randomized clinical trial. J Cancer Surviv. 2015. [Epub ahead of print]

15. Baravelli C, Krishnasamy M, Pezaro C, Schofield P, Lotfi-Jam K, Rogers M, et al. The views of bowel cancer survivors and health care professionals regarding survivorship care plans and post treatment follow up. J Cancer Surviv. 2009:3(2):99-108.

16. Blaauwbroek R, Zwart N, Bouma M, Meyboom-de Jong B, Kamps WA, Postma A. The willingness of general practitioners to be involved in the follow-up of adult survivors of childhood cancer. J Cancer Surviv. 2007;1(4):292-7.

17. Burg MA, Lopez ED, Dailey A, Keller ME, Prendergast B. The potential of survivorship care plans in primary care follow-up of minority breast cancer patients. J Gen Intern Med. 2009;24 Suppl 2:S467-71.

18. Del Giudice ME, Grunfeld E, Harvey BJ, Piliotis E, Verma S. Primary care physicians' views of routine follow-up care of cancer survivors. J Clin Oncol. 2009;27(20):3338-45.

19. Kantsiper M, McDonald EL, Geller G, Shockney L, Snyder C, Wolff AC. Transitioning to breast cancer survivorship: perspectives of patients, cancer specialists, and primary care providers. J Gen Intern Med. 2009;24 Suppl 2:\$459-66.

20. Nissen MJ, Beran MS, Lee MW, Mehta SR, Pine DA, Swenson KK. Views of primary care providers on follow-up care of cancer patients. Fam Med. 2007;39(7):477-82

21. Watson EK, Sugden EM, Rose PW. Views of primary care physicians and oncologists on cancer follow-up initiatives in primary care: an online survey. J Cancer Surviv. 2010:4(2):159-66.

22. Cheung WY, Neville BA, Cameron DB, Cook EF, Earle CC. Comparisons of patient and physician expectations for cancer survivorship care. J Clin Oncol. 2009;27(15):2489-95

23. Aubin M, Vezina L, Verreault R, Fillion L, Hudon E, Lehmann F, et al. Family physician involvement in cancer care follow-up: the experience of a cohort of patients with lung cancer. Ann Fam Med. 2010;8(6):526-32.

24. Mao JJ, Bowman MA, Stricker CT, DeMichele A, Jacobs L, Chan D, et al. Delivery of survivorship care by primary care physicians: the perspective of breast cancer patients. J Clin Oncol. 2009;27(6):933-8.

25. Simone CB, Vapiwala N, Hampshire MK, Metz JM. Cancer patient attitudes toward analgesic usage and pain intervention. Clin J Pain. 2012;28(2):157-62.

26. Grunfeld E, Fitzpatrick R, Mant D, Yudkin P, Adewuyi-Dalton R, Stewart J, et al. Comparison of breast cancer patient satisfaction with follow-up in primary care versus specialist care: results from a randomized controlled trial. Br J Gen Pract. 1999:49(446):705-10.

27. Hudson SV, Miller SM, Hemler J, Ferrante JM, Lyle J, Oeffinger KC, et al. Adult cancer survivors discuss follow-up in primary care: 'not what i want, but maybe what i need'. Ann Fam Med. 2012;10(5):418-27.

28. Bagchi AD, Af Ursin R, Leonard A. Assessing cultural perspectives on healthcare quality. J Immigr Minor Health. 2012;14(1):175-82.

29. Snyder CF, Frick KD, Herbert RJ, Blackford AL, Neville BA, Carducci MA, et al. Preventive care in prostate cancer patients: following diagnosis and for fiveyear survivors. J Cancer Surviv. 2011:5(3):283-91.
30. Garson Jr A, Yong CM, Yock CA, McClellan MB. International differences in patient and physician perceptions of "high quality" healthcare: a model from pediatric cardiology. Am J Cardiol. 2006;97(7):1073-5.

31. Arora NK, Reeve BB, Hays RD, Clauser SB, Oakley-Girvan I. Assessment of quality of cancer-related follow-up care from the cancer survivor's perspective. J Clin Oncol. 2011;29(10):1280-9.

32. Bober SL, Recklitis CJ, Campbell EG, Park ER, Kutner JS, Najita JS, et al. Caring for cancer survivors: a survey of primary care physicians. Cancer. 2009;115(18 Suppl):4409-18.

33. Ferrell BR, Winn R. Medical and nursing education and training opportunities to improve survivorship care. J Clin Oncol. 2006;24(32):5142-8.

34. Grant M, Economou D, Ferrell B, Uman G. Educating health care professionals to provide institutional changes in cancer survivorship care. J Cancer Educ. 2012;27(2):226-32.

35. Metz JM, Devine P, DeNittis A, Jones H, Hampshire M, Goldwein J, et al. A multi-institutional study of Internet utilization by radiation oncology patients. Int J Radiat Oncol Biol Phys. 2003:56(4):1201-5.

36. Chou WS, Liu B, Post S, Hesse B. Health-related Internet use among cancer survivors: data from the Health Information National Trends Survey, 2003-2008. J Cancer Surviv. 2011;5:263-70.

\section{Submit your next manuscript to BioMed Central and take full advantage of:}

- Convenient online submission

- Thorough peer review

- No space constraints or color figure charges

- Immediate publication on acceptance

- Inclusion in PubMed, CAS, Scopus and Google Scholar

- Research which is freely available for redistribution 